American Journal of Pharmaceutical Education 2021; 85 (6) Article 8351.

\title{
BRIEF
}

\section{Assessment of Stress and Quality of Life in Non-native and Native English- speaking Pharmacy Students}

\author{
Ballard Saul, PharmD, ${ }^{\mathrm{a}}$ Sweta Andrews, PharmD, MBA, ${ }^{\mathrm{b}}$ Jennifer Hartman, PharmD, ${ }^{\mathrm{b}}$ Sebastian Perez, \\ PharmD, ${ }^{a}$ Mary L. Chavez, PharmD, ${ }^{a}$ Gabriel A. Frietze, $\mathrm{PhD}^{\mathrm{a}}$ \\ ${ }^{a}$ The University of Texas at El Paso, School of Pharmacy, El Paso, Texas \\ ${ }^{\mathrm{b}}$ Larkin University, College of Pharmacy, Miami, Florida \\ Submitted August 17, 2020; accepted December 23, 2020; published June 2021.
}

\begin{abstract}
Objective. To evaluate the stress and health-related quality of life experienced by native and non-native English-speaking students enrolled in a Doctor of Pharmacy (PharmD) program.

Methods. This study assessed PharmD students at a single institution using a self-administered online questionnaire. The primary outcome of the study was a comparison of Perceived Stress Scale (PSS) scores. Secondary outcomes were the Medical Outcome Study SF-12 Health Questionnaire scores. An independent samples $t$ test was conducted to compare differences between non-native and native English speakers for both primary and secondary outcomes.

Results. The following three criteria were used to evaluate the language status of a student: whether the student preferred to speak English (91/113 participants), whether their primary caregiver as a child spoke English at home (63/113 participants), and whether the student usually thought in English (90/113 participants). Evaluation of the primary outcome of PSS score and secondary outcome of SF-12 mental and physical health revealed no significant differences between native and non-native English speakers based on the three language-related criteria.

Conclusion. The results of this study showed that the native language spoken by a pharmacy student was not directly associated with an increase in stress or decrease in quality of life for students in a PharmD program. However, the survey results did indicate that experiencing more stress correlated with a decrease in students' mental health-related quality of life, which indicates the need for further research to identify students at risk for a decrease in mental health-related quality of life during pharmacy education.
\end{abstract}

Keywords: stress, quality-of-life, language, mental health, physical health

\section{INTRODUCTION}

Experiencing stress, which can be described as a state of bodily or mental tension resulting from factors that tend to alter an existent equilibrium, is a reality affecting many students. ${ }^{1}$ Increased stress and the inability to cope can lead to burnout, which plagues many students. ${ }^{2,3}$ Studies have been conducted to quantify the stress experienced by pharmacy students by year in the program, gender, and ethnicity, and to compare pharmacy students' stress with that of their peers and the general population of the United States. ${ }^{4-6}$ Marshall and colleagues found that pharmacy students have higher levels of stress when compared to similarly aged individuals in the general population. ${ }^{4}$ Additionally, Gupchup and colleagues found that female

Corresponding Author: Ballard Saul, Providence Alaska Medical Center, 3200 Providence Dr., Anchorage, AK 99508. Tel: 907-212-4512. Email: ballard.saul@providence.org pharmacy students reported experiencing higher levels of stress than their male counterparts. ${ }^{5}$ Finally, Votta and colleagues demonstrated that Asian or American Indian/Alaskan Native pharmacy students experienced more stress than Caucasian students. ${ }^{6}$ These studies reveal there are underlying differences in perceived stress based on pharmacy students' demographics.

To address this problem affecting pharmacy students, it is important to identify the underlying cause leading to stress development. As mentioned, Votta and colleagues found there were differing levels of stress between students of different ethnicities. ${ }^{6}$ The authors hypothesized that cultural differences in expectations led to increased stress among students of Asian descent. ${ }^{6}$ Although the expectations of others may contribute to the stress pharmacy students experience, another aspect yet to be studied is the impact of language on pharmacy student stress. Language is an important aspect to consider when evaluating academic-related stress as previous studies have shown that non-native English- 


\section{American Journal of Pharmaceutical Education 2021; 85 (6) Article 8351.}

speaking students face unique difficulties compared to native English-speaking students. ${ }^{7,8}$ Desselle and colleagues found that non-native English-speaking students, on average, scored lower on examinations than their counterparts and reported having more difficulty taking adequate notes. ${ }^{7}$ Diaz-Gilbert and colleagues demonstrated that preceptors perceived that non-native English-speaking students on advanced pharmacy practice experiences (APPEs) had inadequate writing abilities. ${ }^{8}$ An increase in academic difficulties, the rigor of the pharmacy program, and the competitive nature of professional school could contribute to the development of an increased level of academicrelated stress.

Despite studies evaluating stress in pharmacy programs and the effect of language on academic performance, there is currently no literature on the effect of spoken native language on stress in the pharmacy program. In addition, as the student population continues to become more diverse, ${ }^{9}$ it is important to understand the effects of spoken native language on students in a Doctor of Pharmacy (PharmD) program.

This research provides information regarding stress in pharmacy students related to their native language. Additionally, this research serves to identify characteristics leading to the development of academic-related stress and how this effects the student's overall well-being. The primary objective of this study was to determine the effect of a pharmacy student's native language on perceived stress. The secondary objective was to determine the effect of this type of stress on students' health-related quality of life.

\section{METHODS}

This study was approved by the Institutional Review Board at The University of Texas atEl Paso. A 40-item questionnaire was designed that contained four sections: demographics, student stress measurement, health-related quality of life, and self-perception of non-native English speakers.

The 10 questions in the demographics section collected information on the participants age, gender, year in the program, ethnicity, self-reported grade point average (GPA), age at which the participant began speaking English, and language preference. The three items on language preference were used to evaluate primary and secondary outcomes.

Student stress was measured using the questions on the 10-item version of the Perceived Stress Scale (PSS-10), which is a validated scale created by Cohen and colleagues (Cronbach $\alpha=.82) .{ }^{10,11}$ In the present study, the reliability coefficient demonstrated acceptable internal consistency (Cronbach $\alpha=.90$ ). The survey was scored as described by Cohen and colleagues. ${ }^{10,11}$ The numerical answer from each question was added to obtain a participant's total score on a scale of $0-40$, with perceived stress increasing as the total score increased. Four of the questions were reversescored items.

Students' health-related quality of life was evaluated using the previously validated Medical Outcome Study SF-12 Health Questionnaire (Mosier alpha PCS $=0.88$; Mosier alpha $\mathrm{MCS}=0.82$ ) created by Ware and colleagues. ${ }^{12,13}$ The rights to use this tool were obtained from QualityMetric, Inc, prior to survey distribution. This 12-item questionnaire measures health-related quality of life with relation to both physical and mental health, and responses result in a separate composite score for each domain. The score for each domain was calculated as described in the manual obtained from QualityMetrics. ${ }^{15}$ The composite score for each domain is calculated to report physical- and mental health-related quality of life separately. The physical health domain focused on aspects such as physical functioning and pain, while the mental health domain focused on aspects such as social functioning and vitality. Scores are reported as $t$ scores, withlowerscores indicating a decrease in quality of life.

Eight questions were developed by the investigators that were intended to measure students' perception of difficulties experienced in the program. Findings from the eight questions are not reported here as these items were not validated and the analyses did not meet assumptions because of the small sample size.

Information for the study was collected using an online questionnaire administered through QuestionPro (2020 QuestionPro). A list of pharmacy students enrolled in the first three professional years (P1-P3) was obtained from the Office of Student Affairs. A survey overview and invitation were emailed to all students one week prior to survey administration. Because the survey tool required a fourweek recall, the link to complete the survey was provided to students during the fifth week of the spring semester. The amount of stress that pharmacy students experience throughout a semester may vary; thus, the survey was only open for two weeks. A reminder email was sent to students during the two weeks to encourage participation. Although students could complete the questionnaire online at any time during the two-week period, the P1, P2, and P3 classes were each allotted 15-minutes during a scheduled class session to complete the survey. For each class of students for which an $80 \%$ survey completion rate was achieved, a $\$ 50$ gift card was raffled off to a student in that class (ie, a name was drawn at random from the list of students obtained from the university's Office of Student Affairs). Participants were reminded participation was voluntary, confidential, anonymous, and not a program requirement. To facilitate privacy, the data from each completed survey was downloaded from QuestionPro and maintained on the principal investigator's 


\section{American Journal of Pharmaceutical Education 2021; 85 (6) Article 8351.}

Table 1. Demographics of Non-native and Native Englishspeaking Pharmacy Students Who Completed an Assessment of Stress and Quality of Life

\begin{tabular}{|c|c|}
\hline Variable & Total Responses $(\mathrm{N}=113)(\%)$ \\
\hline \multicolumn{2}{|l|}{ Biological sex } \\
\hline Female & $60(53.1)$ \\
\hline Missing data & $1(0.9)$ \\
\hline \multicolumn{2}{|l|}{ Race } \\
\hline White & $84(74.3)$ \\
\hline Multi-ethnic & $17(15.0)$ \\
\hline African American & $5(4.4)$ \\
\hline Pacific Islander & $4(3.5)$ \\
\hline Missing data & $3(2.7)$ \\
\hline \multicolumn{2}{|l|}{ Hispanic or Latino } \\
\hline Yes & $94(83.2)$ \\
\hline No & $18(15.9)$ \\
\hline Missing $^{\mathrm{a}}$ & $1(0.9)$ \\
\hline \multicolumn{2}{|l|}{ Pharmacy year ${ }^{\mathrm{a}}$} \\
\hline $\mathrm{P} 1$ & $57(50.4)$ \\
\hline $\mathrm{P} 2$ & $40(35.4)$ \\
\hline P3 & $15(13.3)$ \\
\hline Missing data & $1(0.9)$ \\
\hline \multicolumn{2}{|l|}{ GPA } \\
\hline $2.00-2.49$ & $1(0.9)$ \\
\hline $2.50-2.99$ & $11(9.8)$ \\
\hline $3.00-3.49$ & $35(31.3)$ \\
\hline $3.50-4.00$ & $65(58.0)$ \\
\hline Missing data & $1(0.9)$ \\
\hline
\end{tabular}

encrypted, company computer. The stored data did not contain any personal identifiable information, thereby ensuring confidentiality for all study participants.

Following completion of the survey, the data were compiled, PSS and SF-12 scores were calculated, and data were analyzed using SPSS software (IBM). The approach to analysis included examining means and standard deviations for continuous variables and percentages for nominal data. Chi-square analyses examined the associations between the dependent variables (PSS, SP-12 Mental Health, and SP-12 Physical Health) and demographic variables. Correlation analyses examined the associations between the outcome variables. Independent samples $t$ tests were used to determine whether language impacted the dependent variables. A Hedges $g$ was calculated to provide an effect size index to accompany each $t$ test. To prevent the inflation of type I error due to multiple testing, a Bonferroni adjustment was set to $\alpha=.017(\alpha=.05 / 3)$ for each family of tests.

An a priori power analysis using G-Power indicated 109 participants were needed to provide an $80 \%$ chance of detecting a moderate effect size $(r=0.236)$ in PSS scores with a 1-tailed test. The effect size of 0.236 was estimated from a study conducted by Mann and colleagues, who assessed the association between proxies of being a nonnative English speaker and the Perceived Stress Scale, with correlations ranging from -0.236 to $-0.398 .{ }^{13}$ Analysis of variance was only conducted if $t$ tests revealed significant findings.

\section{RESULTS}

The study was distributed to 149 pharmacy students enrolled at the institution. Of the 149 students, 113 students (75.8\%) completed the questionnaire. Study participants included 113 pharmacy students (Mean=26.9, $\mathrm{SD}=6.0$ enrolled in a school of pharmacy at a public research university in the Southwest during the didactic portion of the program (P1-P3 years). The majority of the sample identified as female $(53.1 \%)$ and Hispanic $(83.2 \%)$. Approximately a third $(74.3 \%)$ of the participants identified as White, $15.0 \%$ as multi-ethnic, $4.4 \%$ as Black or African American, and $3.5 \%$ as Asian/Pacific Islander. Approximately half

Table 2. Correlation of GPA, Stress, and Quality of Life $(\mathrm{N}=112)$

\begin{tabular}{|c|c|c|c|c|}
\hline & 1 & 2 & 3 & 4 \\
\hline 1. $\mathrm{GPA}^{\mathrm{a}}$ & - & - & - & - \\
\hline 2. PSS & -.18 & - & - & - \\
\hline 3. SF-12 Physical & $.30^{\mathrm{c}}$ & -.14 & - & - \\
\hline 4. SF-12 Mental & $.22^{\mathrm{b}}$ & $-.78^{\mathrm{c}}$ & -.10 & - \\
\hline Mean (SD) & $4.46(0.71)$ & $19.74(7.24)$ & $51.99(7.98)$ & 37.09 (12.79) \\
\hline $\mathrm{N}$ & 112 & 110 & 111 & 111 \\
\hline
\end{tabular}

Abbreviations: GPA = grade point average, PSS = Perceived Stress Scale, SF-12 Physical = Physical domain of Medical Outcome Study SF-12 Health Questionnaire, SF-12 Mental = Mental domain of Medical Outcome Study SF-12 Health Questionnaire

${ }^{a}$ Indicates that Spearman correlations are reported. All other correlations are reported using Pearson's Correlation Coefficient (2-tailed)

${ }^{\mathrm{b}} p<.05$

${ }^{\mathrm{c}} p<.01$ 


\section{American Journal of Pharmaceutical Education 2021; 85 (6) Article 8351.}

(50.4\%) were enrolled in the P1 year, $35.4 \%$ in the $\mathrm{P} 2$ year, and $13.3 \%$ in the $\mathrm{P} 3$ year.

A series of independent samples $t$ tests revealed no difference in stress or quality of life between native and nonnative English speakers (Table 3). However, correlational analyses revealed several significant associations ranging from -0.78 to 0.3 (Table 2). A strong negative correlation emerged between the PSS and the SF-12 Mental domain, indicating an increase in perceived stress was correlated with a decrease in mental health-related quality of life in the pharmacy students completing the survey. In addition, a strong positive correlation emerged between selfreported GPA and the SF-12 Physical domain.

\section{DISCUSSION}

The results of this study did not find a significant association between students' perceived stress or health-related quality of life and native language. These findings are important to pharmacy educators in the continued pursuit of identifying and addressing underlying causes of stress because this study revealed that being a non-native English speaker did not result in increased perceived stress or decreased quality of life.

The current study is not without limitations. First, this project was completed at a single university located on the United States-Mexico border. This limitation is important for a few reasons, given the demographic information, we can assume that most of the non-native English-speaking students had Spanish as their native language. This is important as previous literature has revealed that Asian and American Indian/Alaskan Native students experience an increased level of perceived stress while completing their pharmacy education. ${ }^{6}$ Therefore, the study may not accurately assess the effect of being a non-native English speaker on stress and quality of life, but rather the effect of being a native Spanish speaker. Second, all students in our program are required to study Spanish, which could in turn increase stress for native English speakers. The increased burden on English speakers therefore might have acted to equalize differences in stress between the two populations. Next, having students self-report their GPA may have led to discrepancies between reported and actual figures but would not have altered the findings of the primary or secondary objectives and was necessary to ensure the anonymity of participants. Finally, the institution was a new school of pharmacy and only had a student population of P1, P2, and P3 students, which excluded P4 students completing advanced pharmacy practice experiences (APPEs). Although differences based on year in the program was not an objective, having a large proportion of P1 students may have skewed the average PSS score as stress probably

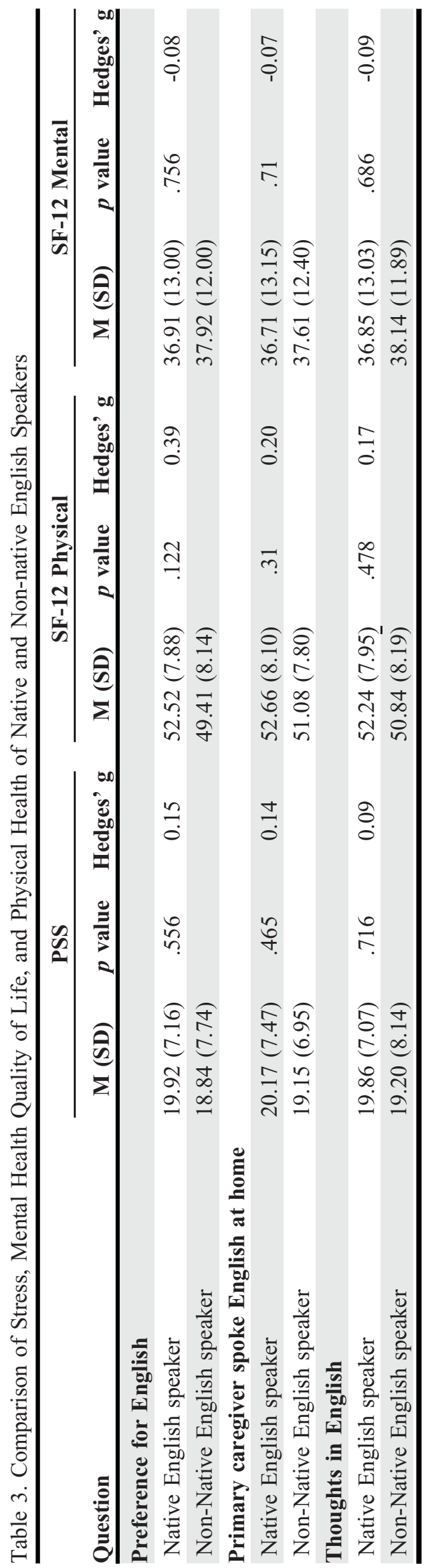




\section{American Journal of Pharmaceutical Education 2021; 85 (6) Article 8351.}

fluctuates as students progress through different phases of the PharmD curriculum and mature personally and professionally. Also, the exclusion of APPE students from the study is an important component to consider because previous publications have demonstrated that non-native English-speaking students completing APPEs were perceived by preceptors to have inadequate writing abilities. ${ }^{8}$

This study revealed correlations that need to be studied for pharmacy schools to be able to better identify students at risk of increased stress and decreased mental health-related quality of life, including the correlation between increased stress and decreased quality of life. Additionally, the study demonstrated non-native English speakers did not experience an increase in stress or decrease in quality of life. However, differences between students based on native language was not within the study design. Therefore, future studies using similar methods need to be conducted to evaluate individual native languages effect on stress and quality of life in pharmacy schools.

\section{CONCLUSION}

When compared to native English speakers, nonnative English-speaking P1 to P3 students in a PharmD program at a single institution did not exhibit differences in stress or quality of life. However, increasing levels of stress were correlated with a decrease in mental health quality of life. As stress and mental health continue to be an important area to monitor and address in pharmacy students, further research is needed that includes broader populations with students who speak other native languages. Also, future assessment of the correlations identified in this study are necessary to better understand factors contributing to stress and quality of life of students enrolled in a pharmacy education program.

\section{REFERENCES}

1. Stress. In: The Merriam-Webster.com Dictionary. MerriamWebster Inc. https://www.merriam-webster.com/dictionary/stress. Accessed June 1, 2021.
2. Montero-Marin J, Prado-Abril J, Demarzo MMP, et al. Coping with stress and types of burnout: explanatory power of different coping strategies. PLOS One. 2014;9(2):e89090. doi:10.137/

journal.pone.0089090

3. Bria M, Baban A, Dumitrascu DL. Systematic review of burnout risk factors among European healthcare professionals. Cogn Brain Behav. X(3);423-452.

4. Marshall LL, Allison A, Nykamp D, et al. Perceived stress and quality of life among doctor of pharmacy students. Am J Pharm Educ. 2008;72(6): 137. doi:10.5688/aj7206137.

5. Gupchup GV, Borrego ME, Konduri N. The impact of student life stress on health-related quality of life among doctor of pharmacy students. Coll Stud J. 2004;38(2):292-301.

6. Votta RJ, Benau EM. Predictors of stress in doctor of pharmacy students: results from a nationwide survey. Curr Pharm Teach Learn. 2013;5(5):365-372. doi:10.1016/j.cpt1.2013.06.014.

7. Desselle SP, Shane PA. Native English speakers and English as a Foreign Language (EFL) students' performance and notetaking in a doctor of pharmacy health systems course. Res Social Adm Pharm. 2018. doi: 10.1016/j.sapharm.2018.09.023

8. Diaz-Gilbert M. Writing skills of advanced pharmacy practice experience students whose first or best language is not English. Am J Pharm Educ. 2005;69(5):101. doi:10.5688/aj6905101.

9. Taylor JN, Taylor DA, Nguyen NT. The pharmacy student population: applications received 2015-16, degrees conferred 2015-16, fall 2016 enrollments. Am J Pharm Educ. 2017;81(7):S8.

10. Cohen S, Kamarck T, Mermelstein R. A global measure of perceived stress. J Health Soc Behav. 1983;24(4):385-396. doi: 10.2307/ 2136404.

11. Baik SH, Fox RS, Mills SD, et al. Reliability and validity of the Perceived Stress Scale-10 in Hispanic Americans with English or Spanish language preference. J Health Psychol. 2019;24(5):628-639. doi: $10.1177 / 1359105316684938$.

12. Ware J, Kosinski M, Keller SD. A 12-Item Short-Form Health Survey: construction of scales and preliminary tests of reliability and validity. Med Care. 1996;34(3):220-233. doi: 10.1097/00005650199603000-00003.

13. Cheak-zamora NC, Wyrwich KW, Mcbride TD. Reliability and validity of the SF-12v2 in the medical expenditure panel survey. Qual Life Res. 2009;18(6):727-735. doi: 10.1007/s11136-009-9483-1

14. Cohen S, Janicki-Deverts D. Who's stressed? distributions of psychological stress in the United States in probability samples from 1983, 2006, and 2009. J Appl Soc Psychol. 2012;42(6):1320-1334. doi: 10.1111/j.1559-1816.2012.00900.x

15. Maruish, ME (Ed.). User's Manual for the SF-12v2 Health Survey. 3rd ed. Lincoln, RI: QualityMetric Incorporated; 2012. 